\title{
Effective Silencing of Dicer Decreases Spore Load of the Honey Bee Parasite Nosema ceranae
}

\author{
Qiang Huang ${ }^{1,2 *}$, Yanping Chen ${ }^{2}$, Peter Neumann ${ }^{1,3,4}$, Wenfeng $\mathrm{Li}^{2}$ and Jay D Evans ${ }^{2 *}$ \\ ${ }^{1}$ Vetsuisse Faculty, Institute of Bee Health, University of Bern, Schwarzenburgstrasse, Bern, Switzerland \\ ${ }^{2}$ USDA-ARS Bee Research Laboratory, BARC-East Building, Beltsville, Maryland, USA \\ ${ }^{3}$ Agroscope, Swiss Bee Research Center, Bern, Switzerland \\ ${ }^{4}$ Bee Protection Laboratory, Department of Biology, Faculty of Science, Chiang Mai University, Chiang Mai, Thailand
}

\begin{abstract}
Nosema ceranae is an intracellular parasite that infects honey bee mid-gut epithelial cells. Previously, we identified microRNA-like small RNAs and found evidence for expression of the N. ceranae gene coding Dicer. The Dicer protein is critical for small regulatory RNA synthesis and RNA interference. In order to test the effects of Dicer on $N$. ceranae reproduction, we designed small interfering RNAs (siRNAs) to suppress Dicer gene expression. After inoculating honey bees with $N$. ceranae spores, siRNAs targeting the gene for Dicer were fed to individual honey bees for three days post infection at $24 \mathrm{~h}$ intervals (siRNA-Dicer group). Additional honey bees were fed with non-specific siRNAs (siRNA-scramble group). The third group of honey bees was inoculated with $N$. ceranae spores without any siRNA treatment (infection group). Overall, siRNA-Dicer significantly inhibited the spore production (ANOVA $P<0.05)$. The honey bees fed with siRNA-Dicer showed $60 \%$ less spores than the honey bees from infection and siRNA-scramble groups (adjusted $P<0.05$ ). The expression of Dicer was not detected at one day post infection (dpi) in the siRNA-Dicer group and the expression level of Dicer remained significantly suppressed at two dpi. The results suggest the gene Dicer is critical for $N$. ceranae reproduction and provide a new insight for this parasite control.
\end{abstract}

Keywords: Microsporidian; RNA interference; MicroRNA; Honey bee; Dicer

\section{Introduction}

Nosema ceranae is an intra-cellular parasite, which infects honey bee mid-gut epithelia cells [1]. After honey bees ingest food contaminated by $N$. ceranae, the spores germinate and extrude polar tubes, which eject the sporoplasm into the host cytoplasm [2]. $N$. ceranae proliferation starts from meronts, leading to daughter sporonts and finally the formation of mature spores $[3,4]$. The infected cells are filled with spores during infection and the cells may then burst to release the spores. Infected honey bees consumed more sugar water [5] and changed their gene expression [6], which suggest energetic parasitism. Infected honey bees also showed suppressed innate immune responses in some cases [7]. Impacts of $N$. ceranae on the health of colonies in the field differ across studies [8,9] but this parasite is reported to directly case honey bee colony collapse in Spain [10].

$N$. ceranae shows high genetic diversity across geographically different locations [11]. The virulence mechanisms of $N$. ceranae remain unclear, with two leading non-exclusive hypothesis for parasite virulence. The first hypothesis suggests that parasites secret hexokinase, thereby accelerating metabolism of infected cells [12]. The second hypothesis suggests that infection suppresses apoptosis of infected cells, improving parasite reproduction [13]. The latter hypothesis is supported by our previous mRNA-deep sequencing efforts [6]. Also, the honey bees that are known to tolerate $N$. ceranae are reported to overcome apoptosis suppression [14]. Our previous small RNA deepsequencing efforts identified novel microRNA-like small RNAs from the $N$. ceranae genome along with evidence for expression of the proteincoding gene Dicer (Ncer_100079) [6,15]. Dicer is a key component of the RNA induced silencing complex, which is critical for regulating developmental and physiological processes and for defending against microbes [16-18]. For many microsporidian species, the gene Dicer is lost [19], including Nosema apis, sister species of N. ceranae [20]. However, N. ceranae has maintained a Dicer homolog. So far, there is no functional analysis of Dicer in N. ceranae. It is also unclear whether $N$. ceranae possesses a functional RNA interference pathway, although prior work has indicated that growth of this parasite is inhibited by RNAi [21]. In order to determine the importance of N. ceranae Dicer for its reproduction, we designed small interfering RNA (siRNA) to target the parasite gene for Dicer. After N. ceranae inoculation, honey bees were fed with siRNA at $24 \mathrm{~h}$ intervals for three days after infection. Our results showed that $N$. ceranae spore load was significantly reduced after reducing the expression level of parasite gene Dicer, indicating a new virulence factor of $N$. ceranae.

\section{Materials and Methods}

\section{Ethics statement}

Apiaries for bee sample collection were maintained by the USDAARS Bee Research Laboratory, Beltsville, Maryland, USA. No specific permits were required for the described studies. The European honey bee (Apis mellifera) used in this study is neither an endangered nor protected species.

\section{siRNA design}

siRNA sequences were designed using the Invitrogen online oligo

*Corresponding authors: Qiang Huang, Institute of Bee Health, Vetsuisse Faculty, University of Bern, Schwarzenburgstrasse 161, CH-3003 Bern, Switzerland, Tel: 9329844585; E-mail: qiang-huang@live.com

Jay D Evans, USDA-ARS Bee Research Laboratory, BARC-East Building 306, Beltsville, Maryland, 20705, USA, Tel: 9329844585; E-mail: Jay.Evans@ARS.USDA.GOV

Received July 22, 2016; Accepted August 08, 2016; Published August 17, 2016

Citation: Huang Q, Chen Y, Neumann P, Li W, Evans JD (2016) Effective Silencing of Dicer Decreases Spore Load of the Honey Bee Parasite Nosema ceranae. Fungal Genom Biol 6: 144. doi:10.4172/2165-8056.1000144

Copyright: ( 2016 Huang Q, et al. This is an open-access article distributed unde the terms of the Creative Commons Attribution License, which permits unrestricted use, distribution, and reproduction in any medium, provided the original author and source are credited. 
design tool (https://rnaidesigner.thermofisher.com/rnaiexpress/). The selected siRNAs were then aligned to the honey bee and $N$. ceranae genomes to avoid off-target matches with Bioedit [22]. Scrambled siRNA, which do not match any genes, were also designed to assess effects of random siRNAs on the parasite. Two siRNAs were designed for the gene Dicer. The two selected siRNAs targeting parasite Dicer are 5'-AGAACCCGAAUUUCAUGCUUGUGAA-3' and 5'-UCUGGACUCUACGACUUCUCCUUUA-3'. The selected scrambled siRNA is 5'-GGAACUCUGACAUACGGUUAUCUAA-3'. The siRNAs were ordered from Invitrogen.

\section{Parasite infection and siRNA feeding}

$N$. ceranae spores were isolated from the midguts of heavily infected honey bee workers and purified using a Percoll gradient procedure [23]. Spores were counted using a Fuchs-Rosenthal haemocytometer and $N$. ceranae species status was verified by species-specific PCR [24]. In order to reduce the impacts of genetic variance of host on the parasite reproduction, all the freshly emerged honey bees were collected from the same colony. Eighty newly emerged workers were individually fed with $2 \mu \mathrm{l}$ sucrose solution without spores, as uninfected group. An additional 80 newly emerged workers were individually fed with $2 \mu \mathrm{l} 50 \%$ sucrose solution containing $10^{5} \mathrm{~N}$. ceranae spores without siRNA treatment as an infection group. Eighty newly emerged workers were individually

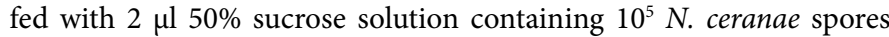
and $1.5 \mu \mathrm{g}$ siRNA targeting parasite gene Dicer as siRNA-Dicer group. Eighty newly emerged workers were individually fed with $2 \mu \mathrm{l} 50 \%$ sucrose solution containing $10^{5} \mathrm{~N}$. ceranae spores and $1.5 \mu \mathrm{g}$ scrambled siRNA as siRNA-scramble group. Forty honey bees were housed in a sterile plastic cup at $34 \pm 1^{\circ} \mathrm{C}, 60 \%$ relative humidity [25]. In order to include cage effects, each group $(\mathrm{N}=80)$ was split into two cups. Sugar water $(50 \%)$ was provided ab libitum as only food source. The honey bees treated with siRNA-Dicer and siRNA-scramble were individually fed for three days post infection at $24 \mathrm{~h}$ intervals.

\section{Sample collection and $\mathrm{qPCR}$}

Dead honey bees were removed daily. Five living honey bees from each cup were collected from 1 to $6 \mathrm{dpi}$ at $24 \mathrm{~h}$ intervals. RNA was extracted from mid-gut tissues of these five honey bees individually using TRIzol and then pooled for replicate qPCR analysis. After $6 \mathrm{dpi}$, surviving honey bees were collected and individual mid-gut tissue was homogenized to count the spore loads using the Fuchs-Rosenthal haemocytometer. We used qPCR to quantify the expression level of the parasite gene Dicer using the described protocols and primers [6]. The honey bee gene $G A P D H$, which is stably expressed during infection, was used as a reference gene to normalize expression levels of the gene Dicer [26]. In total, two biological replicates and two technical replicates were conducted respectively.

\section{Statistics analysis}

In order to achieve a normal distribution, the spore loads were log transformed (base 2). ANOVA was used to determine the significant level of the siRNA treatments on the $N$. ceranae spore load. Posthoc corrections (Bonferroni justification for multiple comparisons) were used for pair-wise comparisons. T-tests were used to determine the effect of siRNA treatment on Dicer expression levels between the siRNA-Dicer group and infection group for each post infection day (Bonferroni adjusted for multiple comparisons).

\section{Results}

$N$. ceranae infection was successful in the infection groups as supported by the spore counting at $6 \mathrm{dpi}$. Spores were not found

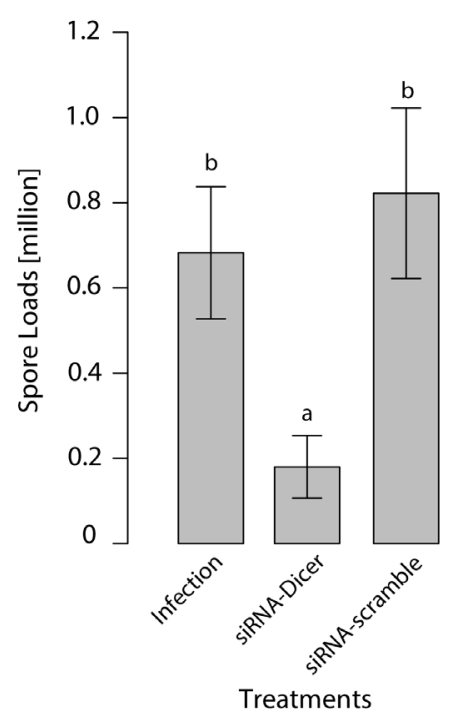

Figure 1: Spore loads of the three experimental groups (Mean $\pm \mathrm{SE}$ ). The spore loads were log transformed with base 2 to achieve the normal distribution during the statistical analysis. Overall, the effect of siRNA treatment on the spore loads was significantly (ANOVA, $\mathrm{df}=2, P<0.05$ ). Honey bees in siRNAs-Dicer group had significantly lower spore loads than both infection and siRNA-scramble groups (adjusted $P<0.05$, Bonferroni adjusted for multiply comparisons). Different letter represents the difference is significant at 0.05 levels.

from the uninfected control group. Overall, the impact of siRNA treatment on spore counts was significant (ANOVA, $\mathrm{df}=2, P<0.05$ ) (supplementary table 1). The honey bees in the siRNA-Dicer group showed significantly lower spore loads than honey bees in both siRNA-scramble and infection groups (adjusted $P<0.05$ ) (Figure 1 ). On average, in siRNA-Dicer group, $N$. ceranae only produced $30 \%$ of the spores isolated from honey bees in infection group. We further quantified the mRNA abundance of Dicer between honey bees in infection and siRNA-Dicer groups. The results showed that the expression level of parasite Dicer was indeed significantly reduced at 2 dpi (adjusted $P<0.05$ ) for honey bees in the siRNA-Dicer group when compared with infection group. The expression level of Dicer was even below the detection level in the honey bees of the siRNADicer group at $1 \mathrm{dpi}$ and Dicer expression was significantly higher at 3 dpi (adjusted $P<0.05$ ) in honey bees from the siRNA-Dicer group compared with the infection group. From 4 to $6 \mathrm{dpi}$, the expression levels of Dicer were not significantly different between the siRNADicer and infection group (Figure 2).

\section{Discussion}

The purpose of this study is to identify the general impacts of parasite Dicer on its reproduction. We selected honey bee host from one colony to reduce the impacts of host genetic variance, even though the diversity has been high within the colony for the polyandry honey bee queen.

In our study, suppressing the expression level of $N$. ceranae Dicer for first two days post infection significantly reduced the spore production. Using siRNA to suppress the expression level of Dicer is challenging, because Dicer itself is a critical component of the RNAinduced silencing complex (RISC) [27,28]. Suppressed expression levels of Dicer might reduce the RNA interference efficiency, in some cases disabling this pathway, as shown for C. elegans [29]. In our study, 


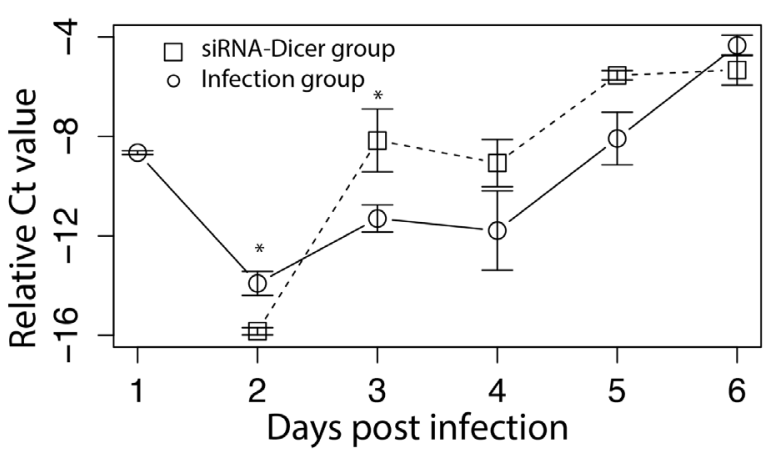

Figure 2: Expression levels of $N$. ceranae Dicer over six days post-infection (Mean $\pm \mathrm{SE}$ ). $\mathrm{X}$-axis represents the day post infection (dpi). Y-axis represents relative $\mathrm{Ct}$ values reflecting Dicer transcript abundance. The $\mathrm{Ct}$ value of Dicer was standardized with the honey bee gene GAPDH, which is stably expressed during infection. Honey bees were fed with siRNAs targeting Dicer for three days post infection. Dicer expression was not detected at $1 \mathrm{dpi}$ in the honey bees fed Dicer specific siRNA as the expression level is too low to detect. Dicer expression was significantly lower in siRNA-Dicer group compared with infection group at 2 dpi (adjusted $P<0.05$ ). However, Dicer was significantly over-expressed in honey bees fed siRNA at 3 dpi (adjusted $P<0.05$ ). From 4 to $6 \mathrm{dpi}$, Dicer expression was not significantly different between siRNA-Dicer and infection groups.

*Represents the difference is significant at 0.05 levels, bonferroni adjusted for multiple comparisons.

Dicer expression was indeed suppressed after siRNA treatment for the first two days post infection. It is necessary to point out that $N$. ceranae is an intra-cellular parasite and the honey bee RNA interference pathway could also be activated to suppress $N$. ceranae gene expression, as suggested from previous study [21]. It is unknown whether honey bees use the siRNA to target the parasite gene Dicer or the parasite used the siRNA to silence the expression level of its own Dicer. The gene for Argonaute is one example for self-silencing. Like Dicer, Argonaute regulates small RNA syntheses and RNA interference [30]. The gene for Argonaute is suppressed with siRNA treatment, leading to enhanced apoptosis of the cell [31]. In our study, the gene for Dicer was significantly over expressed 3 dpi in honey bees treated with siRNADicer when compared with the infection group. It is unclear why Dicer is over expressed in siRNA-Dicer group at $3 \mathrm{dpi}$. Two days of Dicer gene suppression might impact the parasite RNA interference pathway and also as a biological response to gene suppression, arguably explaining why we observed over expression of the gene for Dicer after this time point (Supplementary table 2).

As suggested by our data, N. ceranae produced $70 \%$ fewer offspring spores when Dicer was suppressed for two days. For many microsporidian species, RNAi genes were lost during the evolutionary process and few species have annotated RNAi genes [32]. Still, the functional analyses of the annotated RNAi genes are still missing in Microsporidian species [12,32]. We previously found microRNA-like small RNAs from N. ceranae, supporting genomic and expression data involving plausible RNAi pathway members. Those microRNAlike small RNAs were presumably targeting host metabolism genes. Suppressing the expression level of Dicer might reduce microRNA-like small RNAs synthesis. Consequently, the metabolism of the host can will be regulated by the infection to support parasite reproduction. Non-exclusively, parasite Dicer might be used to regulate its own gene expression for reproduction. For another fungal parasite Botrytis cinerea, it could even manipulate the host RNAi system to attack the host immune response [33]. Even though our current efforts cannot explain how the N. ceranae Dicer regulates parasite reproduction, or specific interactions with host genes, this will be an exciting topic to follow up. Nevertheless, our results provide novel insights into the pathogenesis of $N$. ceranae and point to an additional strategy for the control of this important honey bee parasite.

\section{Acknowledgement}

We thank Dawn Lopez and Michele Hamilton for technical support. We appreciate Michael G Lattorff and Ryan S Schwarz for comments to improve the manuscript. The work is supported by USDA-NIFA grant 2014-67013-21784.

\section{References}

1. Fries I, Feng F, Da Silva A, Slemenda SB, Pieniazek NJ (1996) Nosema ceranae n. sp. (Microspora, Nosematidae), morphological and molecular characterization of a microsporidian parasite of the Asian honey bee Apis cerana (Hymenoptera, Apidae). Eur J Protistol 32: 356-365.

2. Higes M, García-Palencia P, Martín-Hernández R, Meana A(2007) Experimental infection of Apis mellifera honeybees with Nosema ceranae (Microsporidia). J Invertebr Pathol 94: 211-217.

3. Fries I, Martin R, Meana A, Garcia-Palencia P, Higes M (2006) Natural infections of Nosema ceranae in European honey bees. J Apic Res 45: 230-233.

4. Gisder S, Mockel N, Linde A, Genersch E (2011) A cell culture model for Nosema ceranae and Nosema apis allows new insights into the life cycle of these important honey bee-pathogenic microsporidia. Environ Microbiol 13: 404-413.

5. Mayack C, Naug D (2009) Energetic stress in the honeybee Apis mellifera from Nosema ceranae infection. J Invertebr Pathol 100: 185-188.

6. Huang Q, Chen YP, Wang RW (2016) Host-parasite interactions and purifying selection in a microsporidian parasite of honey bees. PLoS One 11: e0147549.

7. Antúnez K, Martín-Hernández R, Prieto L, Meana A, Zunino P, et al. (2009) Immune suppression in the honey bee (Apis mellifera) following infection by Nosema ceranae (Microsporidia). Environ Microbiol 11: 2284-2290.

8. Cox-Foster DL, Conlan S, Holmes EC, Palacios G, Evans JD, et al. (2007) A metagenomic survey of microbes in honey bee colony collapse disorder. Science 318: 283-287.

9. Gisder S, Hedtke K, Möckel N, Frielitz MC, Linde A, et al. (2010) Five-year cohort study of Nosema spp. in Germany: Does climate shape virulence and assertiveness of Nosema ceranae? Appl Environ Microbiol 76: 3032-3038.

10. Higes M, Martín-Hernández R, Botías C, Bailón EG, González-Porto AV, et al. (2008) How natural infection by Nosema ceranae causes honeybee colony collapse. Environ Microbiol 10: 2659-2669.

11. Pelin A, Selman M, Aris-Brosou S, Farinelli L, Corradi N (2015) Genome analyses suggest the presence of polyploidy and recent human-driven expansions in eight global populations of the honeybee pathogen Nosema ceranae. Environ Microbiol 17: 4443-4458.

12. Cuomo CA, Desjardins CA, Bakowski MA, Goldberg J, Ma AT, et al. (2012) Microsporidian genome analysis reveals evolutionary strategies for obligate intracellular growth. Genome Res 22: 2478-2488.

13. Higes M, Juarranz Á, Dias-Almeida J, Lucena S, Botías C, et al. (2013)Apoptosis in the pathogenesis of Nosema ceranae (Microsporidia: Nosematidae) in honey bees (Apis mellifera). Environ Microbiol Rep 5: 530-536.

14. Kurze C, Le Conte Y, Dussaubat C, Erler S, Kryger P, et al. (2015) Nosema tolerant honeybees (Apis mellifera) escape parasitic manipulation of apoptosis. PLoS One 10: e0140174.

15. Huang Q, Evans JD (2016) Identification of microRNA-like small RNAs from fungal parasite Nosema ceranae. J Invertebr Pathol 133: 107-109.

16. He L, Hannon GJ (2004) MicroRNAs: Small RNAs with a big role in gene regulation. Nat Rev Genet 5: 522-531.

17. Ota H, Sakurai M, Gupta R, Valente L, Wulff BE, et al. (2013) ADAR1 forms a complex with Dicer to promote microRNA processing and RNA-induced gene silencing. Cell 153: 575-589.

18. Redfern AD, Colley SM, Beveridge DJ, Ikeda N, Epis MR, et al. (2013) RNAinduced silencing complex (RISC) proteins PACT, TRBP and dicer are SRA binding nuclear receptor co-regulators. Proc Natl Acad Sci USA 110: 6536-6541.

19. Cuomo C, Desjardins C, Bakowski M, Goldberg J, Heiman D, et al. (2012) Comparative genomic analysis of microsporidia species that infect $C$. elegans. Mycoses 55: 16-16. 
Citation: Huang Q, Chen Y, Neumann P, Li W, Evans JD (2016) Effective Silencing of Dicer Decreases Spore Load of the Honey Bee Parasite Nosema ceranae. Fungal Genom Biol 6: 144. doi:10.4172/2165-8056.1000144

Page 4 of 4

20. Chen Yp, Pettis JS, Zhao Y, Liu X, Tallon LJ, et al. (2013) Genome sequencing and comparative genomics of honey bee microsporidia, Nosema apis reveal novel insights into host-parasite interactions. BMC Genomics 14: 451.

21. Paldi N, Glick E, Oliva M, Zilberberg Y, Aubin L, et al. (2010) Effective gene silencing in a microsporidian parasite associated with honeybee (Apis mellifera) colony declines. Appl Environ Microbiol 76: 5960-5964.

22. Hall TA (1999) BioEdit: A user-friendly biological sequence alignment editor and analysis program for Windows 95/98/NT. Nucleic Acids Symposium Series 41: 95-98.

23. Cornman RS, Chen YP, Schatz MC, Street C, Zhao Y, et al. (2009) Genomic analyses of the microsporidian Nosema ceranae, an emergent pathogen of honey bees. PLoS Pathog 5: e1000466.

24. Schwarz RS, Evans JD (2013) Single and mixed-species trypanosome and microsporidia infections elicit distinct, ephemeral cellular and humoral immune responses in honey bees. Dev Comp Immunol 40: 300-310.

25. Evans JD, Chen Y, di Prisco G, Pettis J, Williams V (2009) Bee cups: single-use cages for honey bee experiments. J Apic Res 48: 300-302.

26. Huang Q, Kryger P, Le Conte Y, Moritz RF (2012) Survival and immune response of drones of a Nosemosis tolerant honey bee strain towards $N$. ceranae infections. J Invertebr Pathol 109: 297-302.

27. Hammond SM, Bernstein E, Beach D, Hannon GJ (2000) An RNA-directed nuclease mediates post-transcriptional gene silencing in Drosophila cells. Nature 404: 293-296.

28. Filipowicz W, Bhattacharyya SN, Sonenberg N (2008) Mechanisms of posttranscriptional regulation by microRNAs: Are the answers in sight? Nat Rev Genet 9: 102-114.

29. Ketting RF, Fischer SE, Bernstein E, Sijen T, Hannon GJ, et al. (2001) Dicer functions in RNA interference and in synthesis of small RNA involved in developmental timing in C. elegans. Genes Dev 15: 2654-2659.

30. Teo CH, Pui HP, Othman RY, Harikrishna JA (2011) Comparative analysis of Argonaute gene sequences in bananas (Musa sp.) shows conserved speciesspecific Ago-7 PIWI domains. Genet Resour Crop Evol 58: 713-725.

31. Naoghare PK, Tak YK, Kim MJ, Han E, Song JM (2011) Knock-down of argonaute 2 (AGO2) induces apoptosis in myeloid leukaemia cells and inhibits siRNA-mediated silencing of transfected oncogenes in HEK-293 cells. Basic Clin Pharmacol Toxicol 109: 274-282.

32. Heinz E, Williams TA, Nakjang S, Noel CJ, Swan DC, et al. (2012) The genome of the obligate intracellular parasite Trachipleistophora hominis: New insights into microsporidian genome dynamics and reductive evolution. PLoS Path 8.

33. Weiberg A, Wang M, Lin FM, Zhao H, Zhang Z, et al. (2013) Fungal small RNAs suppress plant immunity by hijacking host RNA interference pathways. Science 342: 118-123.
Citation: Huang Q, Chen Y, Neumann P, Li W, Evans JD (2016) Effective Silencing of Dicer Decreases Spore Load of the Honey Bee Parasite Nosema ceranae. Fungal Genom Biol 6: 144. doi:10.4172/2165-8056.1000144

\section{OMICS International: Publication Benefits \& Features}

Unique features:

- Increased global visibility of articles through worldwide distribution and indexing

- Showcasing recent research output in a timely and updated manner

Special issues on the current trends of scientific research

Special features:

- $700+$ Open Access Journals

$50,000+$ editorial team

Rapid review process

Quality and quick editorial, review and publication processing

Indexing at major indexing services

Sharing Option: Social Networking Enabled

Authors, Reviewers and Editors rewarded with online Scientific Credits

Befter discount for your subsequent articles

Submit your manuscript at: http://www.omicsonline.org/submission 